P-ISSN: 1978-7227 E-ISSN: 2615-3017

dol : https://doi.org/10.30598/barekengvol14iss2pp159-166

National Accredited in SINTA 3, Decree No.: 28/E/KPT/2019

\title{
FLUKTUASI TEMPORAL KELEMBABAN UDARA DI DALAM DAN LUAR EKOSISTEM MANGROVE
}

\section{Temporal Fluctuation of Air Humidity In and Outside The Mangrove Ecosystem}

\author{
Mario Nikolaus Dalengkade* \\ Program Studi Matematika Fakultas Ilmu Alam dan Teknologi Rekayasa Universitas Halmahera \\ Jl. Wari Raya, Tobelo, Halmahera Utara, 97762, Indonesia \\ e-mail:mariodalengkade@gmail.com \\ Corresponding author*
}

\begin{abstract}
Abstrak
Pemodelan kelembaban udara ekosistem mangrove menggunakan fungsi Fourier memperlihatkan siklus fluktuasi temporal. Dimana siklus tersebut dipengaruhi oleh intensitas matahari. Luaran grafik pemodelan kelembaban udara menunjukkan kesamaan untuk posisi 1 dan posisi 3. Berawal dari pukul 19.00 kelembaban udara sebesar $72 \%$ dan terus naik mencapai $85,5 \%$ tepat pukul 04.00 . Kemudian menurun kembali sebesar 59,2\% pada pukul 12.00. Berbeda dengan posisi 9 mulai pukul 19.00 nilai kelembaban udara yakni 71,5\% dan terus naik mencapai 82,5\% tepat pukul 04.00, serta menurun kembali mencapai $65 \%$ pada pukul 12.00. Perbedaan nilai kelembaban udara tersebut karena posisi 1 dan posisi 3 terletak di luar serta tepi hutan mangrove dimana tidak atau kurangnya tutupan kanopi mangrove mengakibatkan proses penguapan sangat cepat terjadi. Sedangkan Posisi 9 terletak di dalam hutan mangrove dimana tutupan kanopi mangrove berperan penting dalam mengendalikan porses penguapan dan meredam intensitas matahari. Disamping itu pengujian korelasi silang menghasilkan time-lag yang bervariasi untuk setiap posisi pengukuran kelembaban udara berdasarkan kedalaman dan tepi ekosistem mangrove.
\end{abstract}

Kata Kunci : kelembaban udara, fungsi Fourier, mangrove, time-lag.

\begin{abstract}
Modeling air humidity in the mangrove ecosystem using Fourier functions shows a cycle of temporal fluctuations. The cycle is influenced by the intensity of the sun. Graphical modeling of air humidity shows similarities for position 1 and position 3. Starting at 19.00 air humidity is $72 \%$ and continues to rise reaching $85.5 \%$ at exactly 04.00 . Then it declined again by $59.2 \%$ at 12.00 . Unlike the 9th position starting at 19.00 the value of air humidity is $71.5 \%$ and continues to rise reaching $82.5 \%$ at exactly 4:00 a.m., and decreases again to reach $65 \%$ at 12.00. The difference in the value of air humidity is because position 1 and position 3 are located outside and the edge of the mangrove forest where no or lack of mangrove canopy cover causes the evaporation process to occur very quickly. While position 9 is located in the mangrove forest where the mangrove canopy cover plays an important role in controlling the evaporation process and reducing the intensity of the sun. Besides that cross-choreal testing produces a time-lag that varies for each position measuring air humidity based on the depth and edge of the mangrove ecosystem.
\end{abstract}

Keywords: air humidity, fourier Function, mangrove, time-lag. 


\section{PENDAHULUAN}

Menurut [1] tercatat Indonesia memiliki luasan mangrove sebesar 3.489.140,68 Ha dari 16.530.000 Ha luasan keseluruhan mangrove yang ada di dunia. Walaupun Indonesia memiliki luasan mangrove terbesar di dunia, tapi terdapat 1.817.999,93 Ha dalam kondisi rusak dan 1.671.140,75 Ha dalam kondisi baik. Rusaknya mangrove menyebabkan terjadi perubahan kondisi fisik lingkungan termasuk iklim mirko [2], [3]. Iklim mikro yakni iklim dengan skala 0,001 hingga $10 \mathrm{~m}$ dan variabel-variabel iklim mikro adalah daya tembus cahaya matahari, daya tembus angin, presipitasi (curah hujan), suhu udara (tanah/udara), kelembaban udara (tanah/udara), dan defisit tekanan uap (VPD) [4], [5].

Baru-baru ini laporan [5] menggunakan formula $f(x)=a+(c+a) /(1+\exp ((x-b) / d))$ untuk mengetahui profil variabel VPD yang terletak di Northeastern Ivory Coast diukur sepanjang transek $400 \mathrm{~m}$ (-200 $\mathrm{m}$ area savana dan $200 \mathrm{~m}$ area hutan). Hasil yang didapatkan menggunakan formula tersebut yakni sepanjang transek $-200 \mathrm{~m}$ dari area savana VPD sebesar 100\% menuju ke tepi hutan berkurang menjadi $70 \%$, dan ke dalam hutan sepanjang transek 200 m menjadi 60\% sewaktu cerah. Sedangkan sewaktu hujan VPD dari arah savana sebesar 30\% menuju tepi hutan menjadi 10\%, kemudian menuju jarak $200 \mathrm{~m}$ ke dalam hutan berkurang menjadi 5\%. Pengukuran intensitas matahari oleh [6] di hutan Pacific Northwest mulai 06.0013.00 mengalami kenaikan $0 \mathrm{~kW} \mathrm{~m}^{-2}-0,9 \mathrm{~kW} \mathrm{~m}^{-2}$. Kenaikan intensitas matahari tersebut diikuti dengan kenaikan suhu udara sejak pukul $06.00-13.00$ sebesar $7{ }^{\circ} \mathrm{C}-27^{\circ} \mathrm{C}$ dari tepi hutan ke area terluar hutan, sedangkan dari tepi kedalam hutan pada pukul yang sama yakni $9{ }^{\circ} \mathrm{C}-19{ }^{\circ} \mathrm{C}$. Laporan-laporan variabel iklim mikro yang telah dikaji di atas memperlihatkan perubahan secara eksponensial, dan kenaikan VPD dan suhu udara sangat dipengaruhi oleh intensitas matahari. Mengutip dari [7] menyatakan bahwa variabel-variabel iklim mikro yang telah di teliti kesemuanya merupakan suatu deret waktu, sehingga dapat di analisis menggunakan fungsi Fourier. Dalam [8], [9], [10], [11], bentuk umum fungsi Fourier yakni ditulis sebagai berikut:

$$
f(t)=\frac{a_{0}}{2}+\sum_{n=1}^{\infty}\left(a_{n} \operatorname{Cos} n \omega t+b_{n} \operatorname{Sin} n \omega t\right)
$$

Penelitian terbaru dari [7] berhasil memodelkan variabel kuat penerangan (intensitas matahari) dan suhu udara di hutan mangrove menggunkana Persamaan (1). Luaran pemodelan tersebut memperlihatkan grafik sinusoidal separuh periode untuk variabel kuat penerangan dan suhu udara. Dimana kuat penerangan pada malam hari bernilai 0, dan mulai pukul 06.00-12.00 sebesar 0.310 lux-59.500 lux. Sama halnya dengan suhu udara mengalami kenaikan mulai pukul $06.00-12.00$ yakni $25{ }^{\circ} \mathrm{C}-35.8{ }^{\circ} \mathrm{C}$.

Menelaah kembali mengenai penelitian iklim mikro hutan mangrove yang telah dipaparkan, maka pertanyaan menarik adalah "Bagaimana perubahan temporal kelembaban udara dan bagaimana respon kelembaban udara terhadap kuat penerangan di hutan mangrove"? Sehingga penelitian mengenai fluktuasi temporal kelembaban udara di hutan mangrove sangat penting, karena menurut [6], [12] variabel iklim mikro merupakan studi lapangan, pemodelan matematik dan data-data iklim mikro dapat menunjukan struktur bentang alam.

\section{METODE PENELITIAN}

Pemodelan variabel iklim mikro dalam penelitian ini didasarkan pada model matematik.Varibel iklim mikro yang diukur yakni kelembaban udara $(H)$ menggunakan fungsi Fourier. Sehingga pemodelan variabel tersebut untuk setiap posisi pengukuran menghasilkan fungsi semata. Fungsi Fourier yang digunakan untuk memodelkan variabel iklim mikro [13], [14] yakni:

dengan

$$
f(t)=T_{0} \sum_{m=0}^{\frac{N}{2}} a_{m} \cos \omega_{m} t+b_{m} \sin \omega_{m} t
$$

$$
\omega_{m}=\frac{2 \pi m}{N}
$$




$$
\begin{aligned}
& a_{m}=\frac{2}{N} \sum_{t=0}^{N-1} f(t) \cos \omega_{m} t \\
& b_{m}=\frac{2}{N} \sum_{t=0}^{N-1} f(t) \sin \omega_{m} t
\end{aligned}
$$

$m$ yakni cacah suku deret Fourier dan $N$ adalah banyaknya data (pasangan data variabel bebas waktu $(t)$ dan variabel terikat kelembaban udara $(H)), f(t)$ adalah kelembaban udara hasil pengukuran lapangan, $a_{m}$ dan $b_{m}$ adalah koefisien Fourier. Pengukuran variabel $H$ selama 25 jam dengan interval waktu 1 jam, sehingga menghasilkan $N=25$. Pengukuran setiap variabel dimulai dari jam 06.00-18.00, sehingga diperoleh data $N$ $=13$. Banyak harmonik yakni $N / 2$, maka untuk 25 data pengamatan, nilai m yakni: $1,2,3, \ldots, 12$. Untuk jumlah $N=13$, data pengamatan $m=1,2,3, \ldots, 6$. Prosedur pemodelan setiap varibel iklim mikro yakni:

1. Menentukan harga koefisien $a_{m}$ dan $b_{m}$ menggunakan Persaman (4) serta Persamaan (5).

2. Menentukan koefisien $c_{m}^{2}=a_{m}^{2}+b_{m}^{2}$.

3. Menentukan sumbangan keragaman: $s_{m}=\left(c_{m}^{2} /(2 . \sigma)\right) * 100$

4. Sinkronisai data antar posisi pengukuran. Sinkronisasi data dilakukan karena pengukuran tidak serempak, tapi berpindah dari posisi satu ke posisi lainnya sepanjang transek. Sinkronisasi data ini dilakukan dengan memasukkan data selisih waktu pengukuran dari posisi satu ke posisi selanjutnya, ke dalam fungsi berikutnya. Sinkronisasi ini tidak mengubah fungsi tapi memberikan harga yang baru untuk setiap posisi.

5. Uji korelasi silang (cross-correlation). Uji korelasi silang ditunjukan guna menghitung time-lag perubahan antara variabel kuat penerang terhadap variabel kelembaban udara. Persamaan yang digunakan untuk menentukan korelasi silang [15] yakni:

$$
\left.r=\sum_{i}^{n}\{(x(i)-m x)) \cdot(y(i-d)-m y)\right\} / \operatorname{sqr}\left\{\sum _ { i } ^ { n } ( x ( ( i ) - m x ) ^ { 2 } \} \cdot \operatorname { s q r } \left\{\sum_{i}^{n}\left(y((i-d)-m y)^{2}\right\}\right.\right.
$$

dengan: $r=$ koefisien korelasi, $n=$ banyaknya pasangan data variabel bebas $(x)$ dan variabel terikat $(y), m=$ konstanta, $i=$ cacah data, $d=$ time-lag antar variabel $x$ serta $y$. Untuk menentukan lag antara $x$ dan $y$ yakni dari nilai maksimal $r$. Proses penentuan lag yakni menggeser salah satu fungsi (misalnya $y$ ) terhadap $x$ (proses iterasi). Pergeseran ini dilakukan dengan cara mengiterasi $d$ dengan interval tertentu. Nilai $d$ awal dapat dipilih sama dengan nol atau menggunakan nilai tertentu jika terdapat acuan lag kedua fungsi. Penggeseran diteruskan selama $r$ bertambah dan dihentikan ketika mencapai nilai tertinggi. Lag kedua fungsi adalah nilai $d$ ketika nilai $r$ maksimal.

\section{HASIL DAN PEMBAHASAN}

\subsection{Topografi Transek Penelitian}

Lokasi penelitian iklim mikro kelembaban udara yakni ditunjukan dalam Tabel 1. Spesies mangrove

\begin{tabular}{|c|c|c|c|c|c|c|c|c|}
\hline \multirow{3}{*}{ 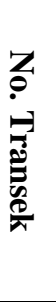 } & \multicolumn{4}{|c|}{ Posisi (Koordinat) Titik Ujung Transek } & \multirow{3}{*}{ 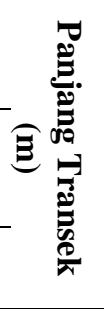 } & \multirow{2}{*}{\multicolumn{3}{|c|}{$\begin{array}{c}\text { Jarak Ke Batas Ekosistem } \\
\text { (m) }\end{array}$}} \\
\hline & \multicolumn{2}{|c|}{ Luar Hutan Mangrove } & \multicolumn{2}{|c|}{ Dalam Hutan Mangrove } & & & & \\
\hline & Lintang & Bujur & Lintang & Bujur & & $\begin{array}{c}\text { Arah } \\
\text { Transek }\end{array}$ & Kiri & Kanan \\
\hline 1 & $0^{0} 511^{\prime} 20.95^{\prime \prime}$ & $124^{0} 42^{\prime} 24.28$ & $0^{0} 51 ’ 20.97 ’$ & $124^{0} 42^{\prime} 23.66^{\prime}$ & 36 & 746 & 764 & 1500 \\
\hline
\end{tabular}
yang tumbuh pada lokasi penelitian didominasi oleh rhizophora dengan tutupan kanopi $85 \%-92 \%$.

Tabel 1. Keterangan Transek Penelitian. 
Topografi transek pengukuran variabel kelembaban udara dalam penelitian ini yakni bagian terluar hutan mangrove merupakan laut dan bagian tepi/batas lebih rendah daripada bagian tengah, serta penggenangan laut tidak merata di lokasi penelitian.

\subsection{Pemodelan Temporal Kelembaban Udara}

Mengacu pada metode penelitian, sehingga dihasilkan data pemodelan kelembaban udara. Tertuang dalam Tabel 2 yakni terdapat 9 posisi pengukuran, tapi dalam tulisan ini hanya memaparkan hasil pemodelan kelebaban udara untuk ke-3 posisi pengukuran yakni Posisi 1 (4 m di luar hutan mangrove), Posisi 3 (tepi hutan mangrove), dan Posisi 9 (32 $\mathrm{m}$ ke dalam hutan mangrove).

Tabel 2. Data Rataan 9 Posisi Pengukuran Kelembaban Udara

\begin{tabular}{|cccc|}
\hline Posisi & Jumlah Data & Rerata & Varians \\
\hline $\mathbf{1}$ & 1853.70 & 74.148 & 86.814 \\
$\mathbf{2}$ & 1854.20 & 74.168 & 86.413 \\
$\mathbf{3}$ & 1855.30 & 74.212 & 84.973 \\
$\mathbf{4}$ & 1864.70 & 74.588 & 71.955 \\
$\mathbf{5}$ & 1869.40 & 74.776 & 67.875 \\
$\mathbf{6}$ & 1873.10 & 74.924 & 63.657 \\
$\mathbf{7}$ & 1877.20 & 75.088 & 61.227 \\
$\mathbf{8}$ & 1880.40 & 75.216 & 59.527 \\
$\mathbf{9}$ & 1881.70 & 75.268 & 58.578 \\
\hline
\end{tabular}

Berdasarkan prosedur pemodelan yang dijelaskan dalam metode penelitian, sehingga dihasilkan data-data iklim mikro kelembaban udara untuk Posisi 1 dirangkum pada Tabel 3.

Tabel 3. Luaran Pemodelan Kelembaban Udara Posisi 1

\begin{tabular}{|c|c|c|c|c|c|}
\hline \multirow{2}{*}{ Posisi } & \multirow{2}{*}{ Harmonik } & \multicolumn{3}{|c|}{ Koefisien Fourier } & \multirow{2}{*}{ Sumbangan Keragaman } \\
\hline & & $A j$ & $B j$ & $C j$ & \\
\hline \multirow{12}{*}{1} & 1 & -3.698 & 12.467 & 169.103 & 97.394 \\
\hline & 2 & 1.292 & -0.392 & 1.822 & 1.050 \\
\hline & 3 & -0.224 & -0.294 & 0.136 & 0.079 \\
\hline & 4 & -0.728 & -0.312 & 0.628 & 0.362 \\
\hline & 5 & 0.655 & -0.031 & 0.429 & 0.247 \\
\hline & 6 & -0.163 & -0.519 & 0.295 & 0.170 \\
\hline & 7 & 0.680 & -0.292 & 0.547 & 0.315 \\
\hline & 8 & -0.227 & -0.034 & 0.052 & 0.030 \\
\hline & 9 & 0.684 & 0.020 & 0.468 & 0.270 \\
\hline & 10 & 0.037 & -0.324 & 0.106 & 0.061 \\
\hline & 11 & 0.057 & -0.073 & 0.009 & 0.005 \\
\hline & 12 & 0.087 & 0.149 & 0.030 & 0.017 \\
\hline Jumlah & 12 & & & & $100 \%$ \\
\hline
\end{tabular}

Bentuk fungsi kelembaban udara Posisi 1 berdasarkan Persamaan 2 tersusun atas data rerata (Tabel 2), banyaknya harmonik, koefisien Fourier $(A j$ dan $B j)$ sehingga menghasilkan total sumbangan keragaman sebesar 100\% (Tabel 3). Fungsi tersebut dapat dituliskan sebagai berikut:

Posisi 1:

$$
\begin{aligned}
H(t)= & 74.148-3.698 \cos (2 \pi t) / 12+12.467 \sin (2 \pi t) / 12+1.292 \cos (4 \pi t) / 12-0.392 \sin (4 \pi t) / 12 \\
& -0.224 \cos (6 \pi t) / 12-0.294 \sin (6 \pi t)-0.728 \cos (8 \pi t) / 12-0.312 \sin (8 \pi t) / 12+0.655 \cos (10 \pi t) / 12 \\
& -0.031 \sin (10 \pi t) / 12-0.163 \cos (12 \pi t) / 12-0.519 \sin (12 \pi t) / 12+0.680 \cos (14 \pi t) / 12-0.292 \sin (14 \pi t) / 12 \\
& -0.227 \cos (16 \pi t) / 12-0.034 \sin (16 \pi t) / 12+0.684 \cos (18 \pi t) / 12+0.020 \sin (18 \pi t) / 12+0.037 \cos (20 \pi t) / 12 \\
& -0.324 \sin (20 \pi t) / 12+0.057 \cos (22 \pi t) / 12-0.073 \sin (22 \pi t) / 12+0.087 \cos (24 \pi t) / 12+0.149 \sin (24 \pi t) / 12
\end{aligned}
$$


Luaran pemodelan kelembaban udara Posisi 3 dengan mengacu pada prosedur pemodelan dalam metode penelitian, maka dihasilkan data-data kelembaban udara fungsi Fourier dirangkum dalam Tabel 2 dan 4.

Tabel 4. Luaran Pemodelan Kelembaban Udara Posisi 3

\begin{tabular}{|c|c|c|c|c|c|}
\hline \multirow{2}{*}{ Posisi } & \multirow{2}{*}{ Harmonik } & \multicolumn{3}{|c|}{ Koefisien Fourier } & \multirow{2}{*}{ Sumbangan Keragaman } \\
\hline & & $A j$ & Bj & $C j$ & \\
\hline \multirow{12}{*}{3} & 1 & -3.807 & 12.289 & 165.502 & 97.385 \\
\hline & 2 & 1.360 & -0.354 & 1.976 & 1.162 \\
\hline & 3 & -0.226 & -0.255 & 0.117 & 0.069 \\
\hline & 4 & -0.709 & -0.318 & 0.604 & 0.355 \\
\hline & 5 & 0.607 & -0.041 & 0.370 & 0.218 \\
\hline & 6 & -0.079 & -0.505 & 0.262 & 0.154 \\
\hline & 7 & 0.580 & -0.345 & 0.455 & 0.268 \\
\hline & 8 & -0.266 & -0.030 & 0.072 & 0.042 \\
\hline & 9 & 0.692 & 0.002 & 0.479 & 0.282 \\
\hline & 10 & 0.061 & -0.257 & 0.070 & 0.041 \\
\hline & 11 & 0.079 & -0.007 & 0.006 & 0.004 \\
\hline & 12 & 0.096 & 0.158 & 0.034 & 0.020 \\
\hline Jumlah & 12 & & & & $100 \%$ \\
\hline
\end{tabular}

Bentuk fungsi kelembaban udara Posisi 3 berdasarkan Persamaan 2 tersusun atas data rerata (Tabel 2), jumlah harmonik, koefisien Fourier ( $A j$ dan $B j$ ) dimana menghasilkan total jumlah keragaman sebesar 100\% (Tabel 4). Sehingga fungsi Fourier kelembaban udara Posisi 3 dituliskan sebagai berikut:

\section{Posisi 3:}

$$
\begin{aligned}
H(t)= & 74.212-3.807 \cos (2 \pi t) / 12+12.289 \sin (2 \pi t) / 12+1.360 \cos (4 \pi t) / 12-0.354 \sin (4 \pi t) / 12 \\
& -0.226 \cos (6 \pi t) / 12-0.255 \sin (6 \pi t) / 12-0.709 \cos (8 \pi t) / 12-0.318 \sin (8 \pi t) / 12+0.607 \cos (10 \pi t) / 12 \\
& -0.041 \sin (10 \pi t) / 12-0.079 \cos (12 \pi t) / 12-0.505 \sin (12 \pi t) / 12+0.580 \cos (14 \pi t) / 12-0.345 \sin (14 \pi t) / 12 \\
& -0.266 \cos (16 \pi t) / 12-0.030 \sin (16 \pi t) / 12+0.692 \cos (18 \pi t) / 12+0.002 \sin (18 \pi t) / 12+0.061 \cos (20 \pi t) / 12 \\
& -0.257 \sin (20 \pi t) / 12+0.079 \cos (22 \pi t)-0.007 \sin (22 \pi t) / 12+0.096 \cos (24 \pi t) / 12+0.158 \sin (24 \pi t) / 12
\end{aligned}
$$

Data-data yang diperlihatkan dalam Tabel 5 yakni merupakan luaran pemodelan kelembaban udara untuk Posisi 9 berdasarkan prosedur pemodelan dalam metode penelitian.

Tabel 5. Luaran Pemodelan Kelembaban Udara Posisi 9

\begin{tabular}{|cccccc|}
\hline & & \multicolumn{3}{c|}{ Koefisien Fourier } & \\
\cline { 2 - 5 } Posisi & Harmonik & $\boldsymbol{A} \boldsymbol{j}$ & $\boldsymbol{B} \boldsymbol{j}$ & $\boldsymbol{C} \boldsymbol{j}$ & \\
\hline & 1 & -5.352 & 9.225 & 113.740 & 97.084 \\
& 1.356 & 0.263 & 1.909 & 1.630 \\
& 2 & -0.288 & 0.068 & 0.088 & 0.075 \\
& 3 & -0.437 & -0.398 & 0.349 & 0.298 \\
$\mathbf{9}$ & 4 & -0.204 & 0.067 & 0.057 \\
& 5 & -0.159 & -0.486 & 0.237 & 0.202 \\
& 6 & 0.393 & 0.040 & 0.156 & 0.133 \\
& 7 & 0.074 & -0.377 & 0.148 & 0.277 \\
& 8 & 0.570 & -0.017 & 0.325 & 0.009 \\
& 9 & 0.033 & -0.095 & 0.010 & 0.083 \\
& 10 & 0.195 & 0.244 & 0.098 & 0.026 \\
\hline Jumlah & 11 & -0.050 & -0.166 & 0.030 & $\mathbf{1 0 0 \%}$ \\
\hline
\end{tabular}


Dalam Tabel 2, Tabel 5 diperlihatkan data rerata, banyak harmonik, koefisien Fourier ( $A j$ dan $B j$ ) dimana manghasilkan menghasilkan total sumbangan keragaman sebesar $100 \%$. Sehingga penulisan bentuk fungsi kelembaban udara Posisi 9 sebagai berikut:

Posisi 9:

$$
\begin{aligned}
H(t) & =75.268-5.352 \cos (2 \pi t) / 12+9.225 \sin (2 \pi t) / 12+1.356 \cos (4 \pi t) / 12+0.263 \sin (4 \pi t) / 12 \\
& -0.288 \cos (6 \pi t) / 12+0.068 \sin (6 \pi t) / 12-0.437 \cos (8 \pi t) / 12-0.398 \sin (8 \pi t) / 12+0.159 \cos (10 \pi t) / 12 \\
& -0.204 \sin (10 \pi t) / 12-0.021 \cos (12 \pi t) / 12-0.486 \sin (12 \pi t) / 12+0.393 \cos (14 \pi t) / 12+0.040 \sin (14 \pi t) / 12 \\
& +0.074 \cos (16 \pi t) / 12-0.377 \sin (16 \pi t) / 12+0.570 \cos (18 \pi t) / 12-0.017 \sin (18 \pi t) / 12+0.033 \cos (20 \pi t) / 12 \\
& -0.095 \sin (20 \pi t) / 12+0.195 \cos (22 \pi t) / 12+0.244 \sin (22 \pi t) / 12-0.050 \cos (24 \pi t) / 12-0.166 \sin (24 \pi t) / 12
\end{aligned}
$$

Berdasarkan bentuk fungsi kelembaban udara Posisi 1, Posisi 3, dan Posisi 9, maka fungsi-fungsi tersebut dapat dilukiskan sebagai berikut:

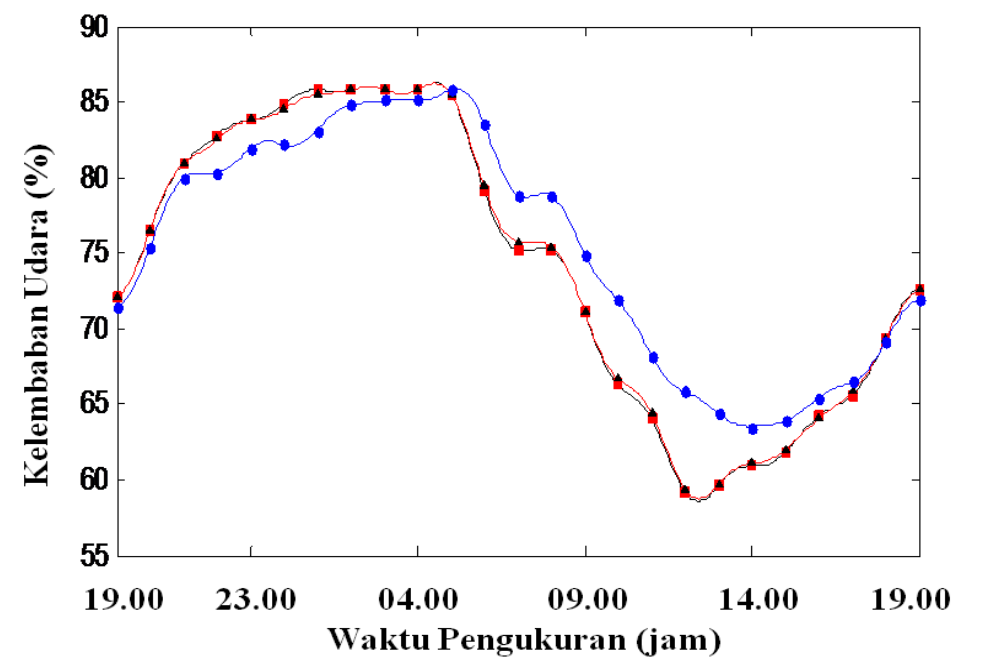

Gambar 1. Grafik Fungsi Untuk Ke-3 Posisi Pengukuran Kelembaban Udara. Posisi 1 Grafik Warna Hitam, Posisi 3 Grafik Warna Merah, dan Posisi 9 Grafik Warna Biru.

Luaran grafik fungsi kelembaban udara Gambar 1 memperlihatkan grafik sinusoidal satu periode. Grafik tersebut berbanding terbalik dengan perubahan temporal kuat penerangan (intensitas matahari) dan suhu udara dalam penelitian [7], [16]. Siklus kelembaban udara yang diperlihatkan oleh grafik sejak pukul 19.00 mengalami kenaikan hingga mencapai kelembaban maksimum $85,8 \%$ tepat pukul 01.00 , dan kembali menurun mulai pukul 04.00 hingga mencapai batas minimum $59,2 \%$ pukul 12.00 . Selain itu selisih antara posisi 1 ke posisi 3 dan posisi 3 ke Posisi 9 pada malam hari yakni 2,7\%, sedangkan siang hari 6,1\%. Khusus Posisi 9 sejak pukul 05.00-14.00 siklus kelembaban udara yang ditampilkan dalam grafik menunjukan presentase $85 \%-64 \%$. Sedangkan Posisi 1 dan Posisi 3 pada pukul yang sama memperlihatkan presentase $85 \%-60 \%$. Hasil ini sejalan dengan [16] yang mengukur kelembapan udara hutan mangrove batas pantai, dimana kelembaban maksimum 86,70\% pukul 03.00 dan minimumnya pukul 13.00 sebesar $59,9 \%$.

\subsection{Respon Kelembapan Udara terhadap Kuat Penerangan}

Penelitian ini tidak memaparkan fluktuasi varibel kuat penerangan, karena sudah di publikasikan dalam [7]. Luaran korelasi silang dan besarnya time-lag untuk setiap posisi dalam transek disajikan dalam Tabel 6. 
Tabel 6. Korelasi Silang dan Time-lag Untuk Setiap Posisi Pengukuran dalam Transek

\begin{tabular}{|ccc|}
\hline \multirow{2}{*}{$\begin{array}{c}\text { Posisi } \\
\text { Pengukuran }\end{array}$} & \multicolumn{2}{c|}{ Time-lag menurut transek dan posisi pengukuran } \\
\cline { 2 - 3 } & Koefisien korelasi & Time-lag \\
\hline $\mathbf{1}$ & 0.965 & 0.6 \\
$\mathbf{2}$ & 0.968 & 0.7 \\
$\mathbf{3}$ & 0.964 & 0.7 \\
$\mathbf{4}$ & 0.960 & 1.0 \\
$\mathbf{5}$ & 0.973 & 1.1 \\
$\mathbf{6}$ & 0.957 & 1.1 \\
$\mathbf{7}$ & 0.964 & 1.3 \\
$\mathbf{8}$ & 0.966 & 1.4 \\
$\mathbf{9}$ & 0.974 & 1.4 \\
\hline
\end{tabular}

Penentuan korelasi silang dan time-lag pada Tabel 6 yakni berdasarkan uraian dalam metode penelitian Persamaan (6), sehingga dihasilkan koefisien korelasi dan time-lag untuk semua posisi dalam transek pengukuran. Dalam Tabel 6 tercatat 9 posisi yakni; 1) Posisi 1 yakni posisi -4 meter di luar hutan bakau;2) Posisi 2 yakni $-2 \mathrm{~m}$ di luar mangrove; 3) Posisi 3 yakni $0 \mathrm{~m}$ tepi mangrove; 4) Posisi 4 yakni $1 \mathrm{~m}$ ke dalam mangrove; 5) Posisi 5 yakni $2 \mathrm{~m}$ ke dalam mangrove; 6) Posisi 6 yakni $4 \mathrm{~m}$ ke dalam mangrove; 7) Posisi 7 yakni $8 \mathrm{~m}$ ke dalam mangrove; 8) Posisi 8 yakni $16 \mathrm{~m}$ ke dalam mangrove dan; 9) Posisi 9 yakni $32 \mathrm{~m}$ ke dalam mangrove. Di samping itu, setiap nilai koefisien yang tertuang dalam Tabel 6 merupakan nilai koefisien korelasi maksimum terjadi saat fungsi kuat penerangan digeser mundur sejauh $t=d$. Dalam hal ini $d$ merupakan time-lag antara perubahan kelembapan udara dengan perubahan kuat penerangan. Visuasilasi setiap bersarnya harga time-lag dipaparkan ke dalam Gambar 2.

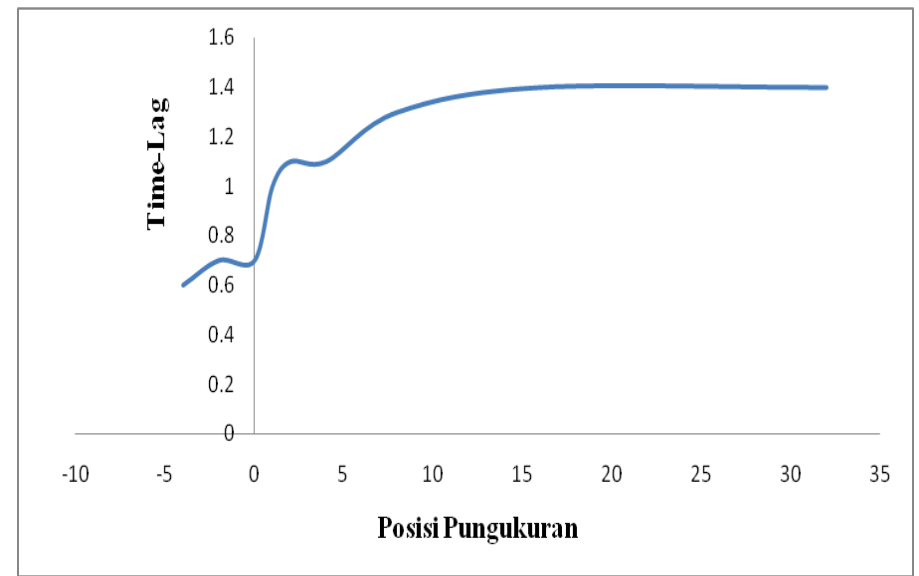

Gambar 2. Grafik Time-lag Kelembaban Udara Terhadap Kuat Penerangan.

Grafik time-lag pada Gambar 2 memperlihatkan perubahan dari Posisi 1 ke Posisi 3 sebesar 0.6 jam hingga 0.7 jam, mengindikasikan bahwa proses penguapan udara sangat cepat terjadi. Sedangkan Posisi 3 sampai Posisi 9 pada rentang 1.0 jam hingga 1.4 jam, mengindikasikan siklus pelepasan udara panas ke atmosfer terhambat dikarenakan tutupan kanopi. Disamping itu siklus kelembapan udara sejelan dengan siklus time-lag suhu udara dalam penelitian [7]. Selain itu, analisis time-lag kelembapan udara menunjukan perbedaan dengan [16] yakni 1.0 hingga $1.2 \mathrm{jam}$. Sehingga dari hasil pembuktian time-lag terhadap kuat penerangan dapat digunakan sebegai parameter untuk pemantauan perubahan iklim mikro mangrove, termasuk perubahan dalam ekosistem mangrove dan lingkungan berbatasan.

\section{KESIMPULAN}

Salah satu parameter iklim mikro yang dikaji dalam penelitian ini yakni kelembaban udara di area hutan mangrove. Dari uraian di atas terbukti bahwa siklus kelembaban mengalami kenaikan pada malam hari dan terjadi penurun pada pagi hari sampai siang hari baik di luar dan di dalam hutan mangrove. Perubahan siklus kelembaban udara karena dipengaruhi oleh intensitas matahari. Ini terbukti dari setiap perubahan time- 
lag untuk setiap posisi pengukuran, dimana besarnya time-lag menandakan bahwa proses difusi termal dari arah vertikal melambat untuk setiap posisi.

\section{DAFTAR PUSTAKA}

[1] D. W. Hadi , "Miliki 23\% Ekosistem Mangrove Dunia Indonesia Tuan Rumah Konferensi Internasional Mangrove 2017," 14 Maret 2017, [Online]. Tersedia: http://ppid.menlhk.go.id/siaran pers/browse/561 [Diakses: 6 Juli 2019].

[2] Y. Mazda and K. Kamiyami, "Tidal Deformation and Inundation Characteristics Within Mangrove Swamps," Mangrove Science, vol. 4, no. 5, pp. 21-29, 2007.

[3] E. Granek and B. I. Ruttenberg, "Changes In Biotic and Abfiiotic Processes Following Mangrove Clearing," Estuarine Coastal and Shelf Science, vol. 80, Issue 4, pp. 555-562, October 2008.

[4] R. J. Davies-Colley, G. W. Payne and M. van Elswijk, "Microclimate Gradients Across a Forest Edge," New Zealand Journal of Ecology, vol. 24, no. 2, pp. 111-121, 2000.

[5] K. J. Hennenberg, D. Goetze, J. Szarzynski, B. Orthmann, B. Reineking, I. Steinke and S. Porembski, "Detection of Seasonal Variability in Microclimatic Borders and Ecotones Between Forest and Savanna," Basic and Applied Ecology, vol. 9.Isssue 3,pp. 275-285, February 2007.

[6] J. Chen, S. C. Saunders, T. R. Crow, R. J. Naiman, K. D. Brosofske, G. D. Mroz, B. L. Brookshire and J. F. Franklin, "Microclimate in Forest Ecosystem and Landscape Ecology," BioScience, vol. 49, no. 4, pp. 288-297, April 1999.

[7] M. N. Dalengkade, "Pemodelan Reaksi Suhu Udara Terhadap Penyinaran Cahaya Matahari Dalam Hutan Bakau," Barekeng, vol. 13, no. 2, pp. 061-068, Agustus 2019.

[8] H. Dym and H. P. McKean.Fourier Series and Integrals. New York: Academic Press Inc, 1972.

[9] M. R. Spiegel. Fourier Analisis. New York: McGraw-Hill Inc, 1974.

[10] P. Bloomfield. Fourier Analysis of Time Series: An Introduction. New York: John Wiley \& Sons Inc. 2000.

[11] G. S. Campbell. An Introduction to Environmental Biophysics. New York: Springer-Verlag, 1977.

[12] Q. T. Vo, C. Kuenzer, Q. M. Vo, F. Moder and N. Oppelt, "Review of Valuation Methods for Mangrove Ecosystem Services," Ecological Indicators, vol. 23, pp. 431-446, April 2012.

[13] C. S. Medellu and D. Tulandi, "Parameter: The Area of Microclimate Gradient Diurnal Dynamic for Characterization and Monitoring of Forest Ecosystem and Environment," International Journal of Environment Agriculture and Biotechnology, vol. 3, Issue-3, pp. 934-943, May-June 2018.

[14] C. S. Medellu, "The Area and Index of Diurnal Dynamic of Microclimate Gradient as a Mangrove-Environment Interaction Parameter," Journal of Natural Sciences Research, vol. 3, no. 14, pp. 68-77, 2013.

[15] V. Bewick, L. Cheek and J. Ball, "Statistics review 7: Correlation and regression," Critical Care, vol. 7, no. 6, pp. 451-459, November 2003.

[16] M. N. Dalengkade, "Profil 24 Jam Kuat Penerangan, Suhu Udara, Kelembaban Udara Di Luar Dan Di Dalam Hutan Mangrove" Barekeng, Vol. 14, no.1, pp. 047-058, Maret 2020. 